\title{
Futility-of-care decisions in the treatment of mori- bund intensive care patients in a developing country
}

\author{
[L'acharnement thérapentique pour des moribonds à l'unité des soins intensifs \\ dans un pays en développement]
}

Seetharaman Hariharan MD, Harley S.L. Moseley FFARCS, Areti Y. Kumar MD, Errol R. Walrond FrCs, Ramesh Jonnalagadda MS

Purpose: To analyze the characteristics of moribund patients in a surgical intensive care unit (ICU) and highlight the dilemmas inherent in treating such patients.

Methods: Data on all patients admitted to the surgical ICU during the period of three years from July 1999 to June 2002 were collected prospectively. Data were collected on very ill patients who died, in whom it appeared obvious that treatment could not have improved their condition and whose death could have been anticipated. The case notes were subjected to further analysis to determine the difficulties encountered in managing patients whose therapy was considered to be futile.

Results: Of 662 admissions, 100 (15.1\%) died and 30 (4.5\%) patients were treated aggressively, even after a prognosis which reflected futile treatment. The overall mean length of stay for survivors was $7.5 \pm 9.0$ [standard deviation (SD)] days and that for the non-survivors was $12.8 \pm 18.1(\mathrm{SD} ; P<0.001)$. The cost incurred for the treatment of non-survivors was significantly higher than that for the surviving patients. The factors relating to the decisions to continue futile therapy were age of the patient, legal considerations, family wishes and differing opinions between treating physicians.

Conclusion: Consideration of futility during end-of-life care did not receive adequate attention in this unit which incurred additional human and material resources.

Objectif : Analyser les caractéristiques des patients moribonds d'une unité de soins intensifs chirurgicaux (USI) et souligner les dilemmes inhérents au traitement de ces patients.

Méthode : Nous avons rassemblé prospectivement les données concernant tous les patients admis à l'USI chirurgicaux de juillet 1999 à juin 2002. Nous avons gardé les données sur des patients gravement malades qui sont décédés, pour qui il est apparu évident que le traitement n'avait pas amélioré la condition et dont la mort pouvait être prévue Les informations ont été ensuite soumises à une analyse sup- plémentaire afin de préciser les difficultés de prise en charge de ces patients dont le traitement était considéré inutile.

Résultats : Des 662 patients admis, 100 (15,1\%) sont décédés et 30 (4,5\%) ont reçu un traitement énergique, même après un pronostic qui révélait l'inutilité du traitement. La moyenne globale de la longueur du séjour hospitalier des survivants a été de 7,5 \pm 9,0 jours [écart type] et celle des non survivants a été de $12,8 \pm 18,1$ jours (écart type ; $P<0,001$ ). Le coût du traitement des non survivants a été significativement plus élevé que celui des survivants. Les facteurs qui ont amené à poursuivre un traitement inutile étaient l'âge du patient, des préoccupations légales, des demandes de la famille et des divergences d'opinions entre les médecins traitants.

Conclusion: On ne se préoccupe pas suffisamment de l'inutilité des soins aux personnes en fin de vie à l'USI chirurgicaux, ce qui entraîne l'utilisation de ressources humaines et matérielles supplémentaires.

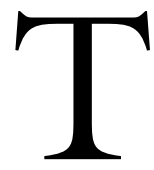

HE concepts of futility and end-of-life care are much-discussed topics in North America. ${ }^{1}$ However, these practices are yet to be widely instituted in developing countries like ours, although our intensive care units (ICU) care and performance are comparable to those in more developed countries. ${ }^{2}$ End-of-life care in the ICU has been proposed as a potentially important area of research. ${ }^{3}$ We examine the current situation with data collected from patients admitted to the surgical ICU of the Queen Elizabeth Hospital, Barbados, over a period of three years.

\section{Hospital and ICU setting}

Barbados is a small island of the English-speaking Caribbean, with a population of 254,000 and a

From the Department of Anaesthesia, Surgery and Surgical Intensive Care, Queen Elizabeth Hospital, Barbados, West Indies. Address correspondence to: Dr. Seetharaman Hariharan, Department of Anaesthesia and Surgical Intensive Care, Queen Elizabeth

Hospital, Barbados, West Indies. Phone: 1-246-436-6450; Fax: 1-246-429-5374; E-mail: hariharan@sunbeach.net Accepted for publication March 13, 2003.

Revision accepted June 3, 2003. 
tourism-based economy. The Queen Elizabeth Hospital, Barbados, is a 650-bed tertiary care centre, affiliated to the University of West Indies and a referral centre for several Caribbean countries. The surgical ICU in the Queen Elizabeth Hospital is a six-bed unit, admitting adult patients from cardiothoracic surgery, neurosurgery, general surgery, obstetrics and gynecology, otolaryngology, orthopedic surgery and urology. A qualified anesthesiologist cares for the patients around the clock under the supervision of a senior colleague. Admitting surgeons visit the patients daily. Treatment orders are written by the anesthesiologist and decisions are made by the team consisting of the parent surgical unit and the anesthesiologist. Most of the time the surgical team meets the family members, although the duty anesthesiologist meets them on occasions. Although the hospital has performed some successful renal transplants, at present we do not have an active renal-transplant unit, despite the considerable number of end-stage renal failure patients requiring chronic dialysis.

\section{Methods}

Approval of the Hospital Ethics Committee was obtained prior to the study. All patients admitted consecutively to the surgical ICU over a period of three years from July 1999 through June 2002 were included for collection of data. Demographic data, such as the age and gender of the patients, the diagnosis, patient outcome and the length of stay were recorded for all patients. Acute Physiology and Chronic Health Evaluation (APACHE) II score was recorded on admission for the non-cardiac surgery patients. The cost incurred was calculated from previous research ${ }^{2}$ which used a cost block model developed in the United Kingdom. The mean length of stay was used to calculate the average cost of a survivor and nonsurvivor. From the group of patients who died, we selected patients whose treatment was considered to be futile. The criteria we included for this categorization were:

1) Brain-dead patients - using standard clinical criteria;

2) Patients who had brain damage and remained in a vegetative state until death - in accordance with the definition of the vegetative state ${ }^{4}$

3) Patients who were admitted in a conscious state, but subsequently became unresponsive; not responding to therapy for more than two weeks and at least two consultants agreed that further management of the patient would be futile.

These patients were admitted under the care of different surgical specialties, and there were clear dilem- mas on how to proceed with further management. From the case notes of these patients, we recorded the events of their complete stay in the ICU and analyzed the events during the end-of-life ICU care. The documentation in the case notes during the daily rounds included opinions of the primary surgeon, the intensivist as well as the content of discussions with the patient's relatives if this was undertaken. These helped to identify and categorize the factors which influenced the decisions to continue therapy in these patients.

Student's $t$ test was used for statistical analysis of continuous variables, such as age, APACHE II score, length of stay and treatment cost comparing survivors and non-survivors.

\section{Results}

During the three-year period of the study, 662 patients were admitted to the surgical ICU, of which 100 patients died (mortality rate $15.1 \%$ ). The demographic data are given in Table I. The comparison of length of stay is given in Table II. The age, APACHE II scores of the non-cardiac surgery patients and the overall length of stay of the non-survivors were significantly higher than that of the survivors. The costs involved in treating the survivors and non-survivors are given in Table II, which also showed a significant difference. Among the 100 who died, 30 patients (4.5\% of the total 662$)$ fit into the criteria of undergoing futile therapy in the ICU. The categories of patients who were classified to have undergone futile management are given in Table III.

When the case notes of these 30 patients were analyzed it was found that:

1) In the majority of the patients $(n=26)$, even after an agreement on the futility of treatment, there was no attempt to withhold any form of therapy;

2) In four patients, some treatment modalities such as antibiotic therapy, total parenteral nutrition and inotropic support were withdrawn;

3) Mechanical ventilatory support was not withdrawn in any patient.

The main factors identified as influencing decisions of futility of care were:

\section{Age of the patient}

There were seven brain-dead patients who were less than $30 \mathrm{yr}$ of age and no attempts were made to withdraw any form of management in these patients. All of them received antibiotics and inotropic support, along with ventilator support until death. On the other hand, a 74-yr-old patient who had a gunshot wound to the head had brain-death confirmed earlier and no 
TABLE I Demographic data and APACHE II scores

\begin{tabular}{|c|c|c|c|}
\hline Variable & $\begin{array}{l}\text { Overall } \\
(n=662)\end{array}$ & $\begin{array}{l}\text { Survivors } \\
(n=562)\end{array}$ & $\begin{array}{l}\text { Non-survivors } \\
(n=100)\end{array}$ \\
\hline Age $($ mean $\pm S D)$ & $51.5 \pm 19.6$ & $50.7 \pm 18.6$ & $56.3 \pm 23.9^{*}$ \\
\hline Age $\geq 70$ yr $(n-\%)$ & $135(20.4)$ & $92(16.4)$ & $43(31.9)$ \\
\hline \multicolumn{4}{|l|}{ Gender $(n-\%)$} \\
\hline Male & $354(53.5)$ & $297(52.8)$ & $57(57)$ \\
\hline Female & $308(46.5)$ & $265(47.2)$ & $43(43)$ \\
\hline $\begin{array}{l}\text { Non-cardiac surgery } \\
\text { patients }(n-\%)\end{array}$ & $471(71.1)$ & $383(68.1)$ & $88(88)$ \\
\hline $\begin{array}{l}\text { Cardiac surgery } \\
\text { patients }(n-\%)\end{array}$ & $191(28.9)$ & $179(31.9)$ & $12(12)$ \\
\hline $\begin{array}{l}\text { APACHE II } \\
(n=471 ; \text { mean } \pm \text { SD })\end{array}$ & $10.7 \pm 7.5$ & $8.7 \pm 5.9$ & $21.2 \pm 5.9 \dagger$ \\
\hline
\end{tabular}

APACHE II = Acute Physiology and Chronic Health Evaluation; $\mathrm{SD}=$ standard deviation. ${ }^{*} P<0.01 ; \dagger P<0.001$.

TABLE II LOS (days) and costs

\begin{tabular}{llll}
\hline Category & $\begin{array}{l}\text { Overall } \\
(\text { mean } \pm S D)\end{array}$ & $\begin{array}{c}\text { Survivors } \\
(\text { mean } \pm S D)\end{array}$ & $\begin{array}{l}\text { Non-survivors } \\
(\text { mean } \pm S D)\end{array}$ \\
\hline $\begin{array}{l}\text { Non-cardiac surgery } \\
\text { patients LOS }(n=471)\end{array}$ & $8.6 \pm 11.4$ & $7.9 \pm 9.9$ & $11.7 \pm 15.9 \dagger$ \\
$\begin{array}{l}\text { Cardiac surgery patients } \\
\text { LOS }(n=191)\end{array}$ & $7.6 \pm 10.1$ & $6.7 \pm 6.7$ & $20.8 \pm 29.3 \ddagger$ \\
$\begin{array}{l}\text { Cost per patient } \\
\text { (Barbados \$; one US dollar }=\text { two Barbados dollars })\end{array}$ \\
\hline
\end{tabular}

LOS = length of stay; $\mathrm{SD}=$ standard deviation. $\dagger P=0.004 ; \ddagger P<$ 0.001 .

therapy other than mechanical ventilation was instituted until his death. Among eight patients who were unresponsive after laparotomy, four patients in whom some therapeutic modalities were withdrawn were more than $80 \mathrm{yr}$ old; the other four patients in whom no support was withdrawn were in their sixties.

\section{Legal considerations}

Medico-legal cases $(n=9)$ which were coroner cases where some felony may have been committed, received more support (such as continuous escalation of the dose of noradrenaline) than did their nonmedico-legal counterparts.

\section{Family influences}

In many cases $(n=24)$ the high hopes of the family members for recovery and their consistent requests to the surgeons contributed to the continuation of therapy. In two instances, some of the patient's relatives lived abroad and the surgeons were more reluctant in stopping any form of support due to fear of litigation.
TABLE III Categories of patients who underwent "futile" management $(n=30)$

\begin{tabular}{|c|c|c|c|}
\hline Category & Etiology & $\begin{array}{l}\text { Treatment } \\
\text { given } \neq\end{array}$ & Number \\
\hline \multirow[t]{3}{*}{$\begin{array}{l}\text { Brain-death } \\
(n=9 ; 30 \%)\end{array}$} & $\begin{array}{l}\text { Motor vehicle } \\
\text { accidents }\end{array}$ & $\mathrm{V}, \mathrm{I}, \mathrm{A}$ & 4 \\
\hline & $\begin{array}{l}\text { Gunshot wound } \\
\text { to head }\end{array}$ & $\mathrm{V}, \mathrm{I}$ & 2 \\
\hline & Multiple trauma & $\mathrm{V}, \mathrm{I}, \mathrm{A}$ & 3 \\
\hline \multirow[t]{2}{*}{$\begin{array}{l}\text { Vegetative state } \\
(n=7 ; 23 \%)\end{array}$} & Postcardiac arrest & $\mathrm{V}, \mathrm{I}, \mathrm{A}, \mathrm{T}, \mathrm{O}$ & 5 \\
\hline & Postneurosurgery & $\mathrm{V}, \mathrm{A}, \mathrm{I}, \mathrm{T}, \mathrm{O}$ & 2 \\
\hline \multirow{5}{*}{$\begin{array}{l}\text { Other categories* } \\
(n=14 ; 47 \%)\end{array}$} & Postlaparotomy & $\mathrm{V}, \mathrm{I}, \mathrm{A}, \mathrm{T}, \mathrm{O}$ & 8 \\
\hline & Postcardiac surgery & $\mathrm{V}, \mathrm{I}, \mathrm{A}, \mathrm{T}, \mathrm{O}$ & 3 \\
\hline & Post ENT surgery & $\mathrm{V}, \mathrm{I}, \mathrm{A}, \mathrm{T}, \mathrm{O}$ & 1 \\
\hline & $\begin{array}{l}\text { High cervical } \\
\text { spine injury }\end{array}$ & $\mathrm{V}, \mathrm{I}, \mathrm{A}, \mathrm{T}, \mathrm{O}$ & 1 \\
\hline & $\begin{array}{l}95 \% \text { third degree } \\
\text { burns }\end{array}$ & $\mathrm{V}, \mathrm{I}, \mathrm{A}, \mathrm{T}, \mathrm{O}$ & 1 \\
\hline
\end{tabular}

ENT $=$ otorhinolaryngology. * More than two weeks of unresponsiveness and at least two consultant physicians' agreement to the futility of further therapy. $\ddagger$ Treatment given after futility was apparent: $\mathrm{V}=$ mechanical ventilatory support; $\mathrm{A}=$ antibiotics (more than one broad-spectrum antibiotic used); $\mathrm{I}=$ inotropic support in the form of dopamine, dobutamine, milrinone, noradrenaline and vasopressin; $\mathrm{T}=$ total parenteral nutrition; $\mathrm{O}=$ oth ers such as transfusions, amiodarone, magnesium, desmopressin, hormones, antioxidants etc.

\section{Surgeons' refusal to accept futility in a postoperative patient}

In 12 patients, a surgeon's disagreement with the other consultants involved in the management to accept futility was an important reason for prolonging support.

\section{Discussion}

There are many definitions for medical futility. The Council on Ethical and Judicial affairs of the American Medical Association offers perhaps the most lucid definition: "In the course of treating a critically ill patient, it may become apparent that further intervention will only prolong the final stages of the dying process; at this point further intervention is described as futile." 5 Brody and Halevy have categorized futility into four simple types to provide some clarity: 1) physiologic futility; 2) imminent demise futility; 3 ) lethal condition futility; and 4) qualitative futility. ${ }^{6}$ Although we identified a number of patients conforming to all these categories during the study period, there was no sin- 


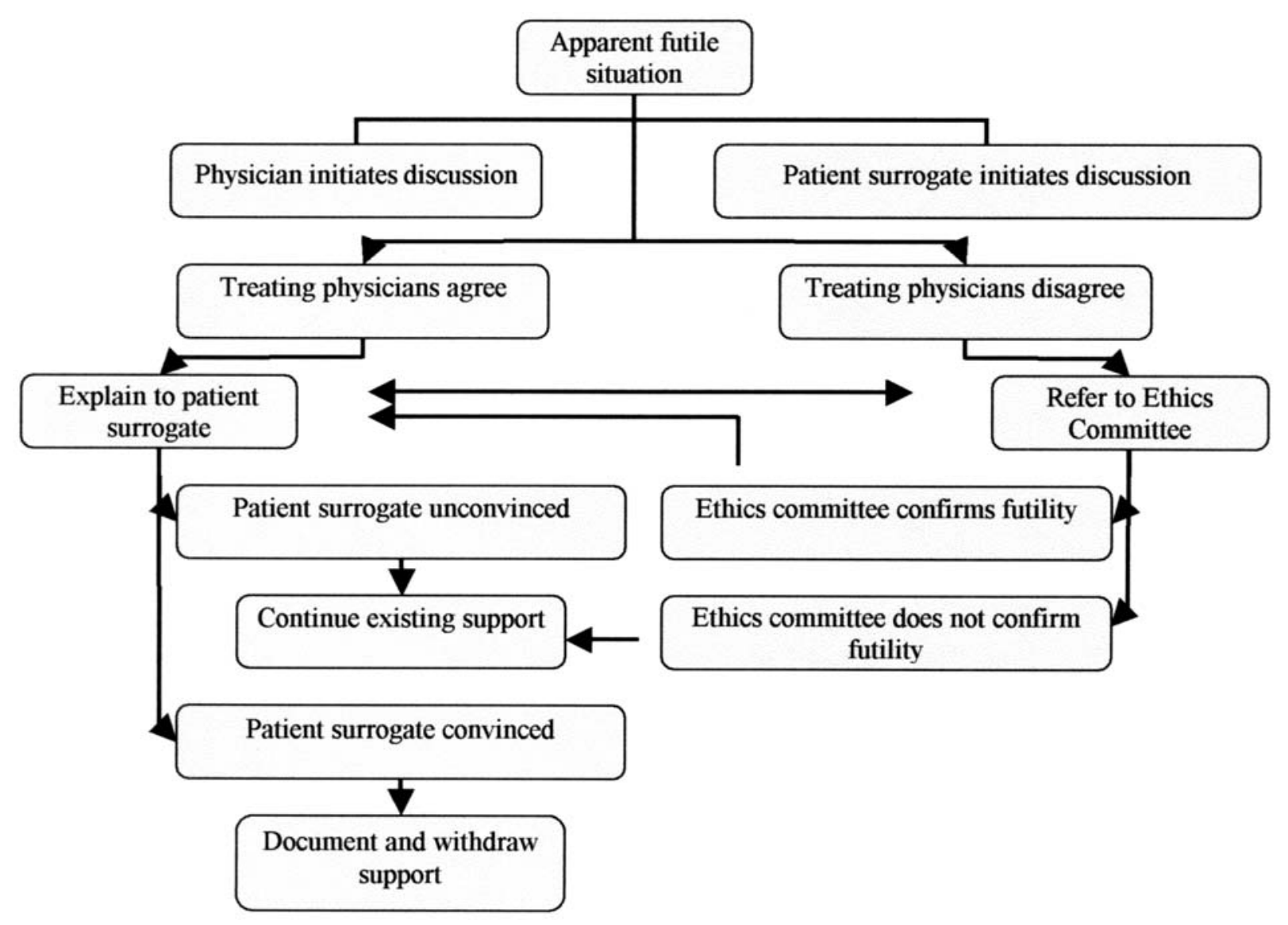

FIGURE Proposed algorithm to manage a futile situation in the intensive care unit.

gle case where the decision of futility of care was used to withhold life-support.

Many physicians are hesitant to recognize futility of care because of religious beliefs, a feeling of guilt and fear of litigation. Critical care nurses report frustrations at the different behaviours of physicians during end-of-life care. ${ }^{7}$ The study to understand prognoses and preferences for outcomes and risks of treatment showed unwanted life-sustaining treatment and insufficient palliative care at the end of life. ${ }^{8}$ The heartening aspect of our ICU care was that according to the case notes, all the patients (except the brain-dead) received adequate sedation until death.

On the other side of the coin, in North America when physicians invoke the concept of futility during the end-of-life care, many biases are reported to influence decision-making. Non-white race of the patient and diagnoses of aquired immunodeficiency syndrome and malignancies have been cited to be important rea- sons to withdraw support. ${ }^{9}$ The alarming aspect of practicing the concept is that, most often, decisions were taken unilaterally by the physicians both in North America and Europe. ${ }^{10,11}$ Very old age and malignancies with metastases were some factors in our ICU which influenced withdrawal of some modalities of therapy in a few patients. However, respiratory support was not withdrawn on any occasion although the same moral conviction is required to withdraw one form of support or another. ${ }^{12}$ Clearly ventilator support is seen by our physicians as the ultimate tool in life-support which cannot be withdrawn without taking personal responsibility for the death of a patient.

The main aim of critical care since the time of its evolution as a specialty has been "prevention of death." 4 The media have been powerful enough to disseminate misinformation about cardiopulmonary resuscitation (CPR) and life-support ${ }^{13}$ and the majority of non-medical individuals think that with the 
advanced treatments available in modern medicine, most lives can be saved. The family members' high hopes for the survival of patients in our ICU may perhaps have been due to these misconceptions.

Although the continuation of futile intensive therapy is often effected by either physician or the patient surrogate, North American courts have tended to decide in favour of patients and surrogates rather than the physicians. ${ }^{14}$ In our situation, both physician and surrogate factors were responsible for the continuation of futile therapy. The surgeons' reluctance to accept futility of care in some of our postoperative patients may have been due to the perception that it would be misconstrued as a "failure" of the surgical treatment.

Different countries have different legal structures to support physicians' decisions made on the basis of futility of care. Currently, there is no statute in Barbados law that makes provision for discontinuation of life-support measures, even if the patient is proven to be brain-dead; nor is there recognition of Living Wills or Do-NotResuscitate instructions given by a patient. However, all of these measures are well recognized in the common law and can be defended in a court. Proposals have been made to put a statute in place that would allow the transplantation of cadaver organs.

Outside these legal implications, the most important solution for this issue is effective communication with the patient surrogate and provision of adequate information to avoid mistrust. There is evidence that after adequate explanation and the proper knowledge about CPR and its outcome, the percentage of residents of old-age homes opting for CPR decreased by half. ${ }^{15}$ When the physician-surrogate discussion becomes clearly focused towards the ultimate "goal" of relief of distress for all involved rather than the "treatment" of the condition alone, planning becomes easier and consensual. This was clearly missing in our situation. There appears to have been no active discussions among the surgeon, the anesthesiologist or the patient's relatives as a group in most of our situations. Our surgical ICU is an area where surgeons of different specialties admit patients and have conflicting views that often do not coincide the anesthesiologist's. There were many decisions made by different professionals regarding the commission and omission of certain therapeutic modalities. It requires a team effort for resolving the important problems of decision-making in an ICU. ${ }^{16}$ Another factor is that there have been few attempts to involve the Clinical Ethical Committee in the hospital in the decision-making for individual patients; this suggests a lack of insight in the area of ethics and the role of an ethics committee. Effective use of chaplain services in the ICU has been shown to be helpful in averting misconceptions and litigations. ${ }^{17}$ This was also missing in our ICU in an organized basis. We strongly recommend that a trained counselor be attached to the ICU to facilitate discussion with patient surrogates and to coordinate with physicians. We further suggest that there is a need for local/Caribbean guidelines which take into consideration the unique local socio-cultural/ethnic variations. When there is a dilemma and when there are no clear guidelines and coordinated efforts to deal with the situation, we propose an algorithm (depicted in the Figure) to assist in decision-making.

Decisions about futility of care should not be made primarily on the grounds of rationing where resources are allocated to a patient whom the physicians think is salvageable but withheld from the so-called hopeless patient. ${ }^{18}$ In our situation the issue is complicated by the fact that ICU therapy is offered free of cost to the citizens of Barbados. Patient surrogates often tell physicians to try everything possible until the end, particularly because the cost factor is not apparent. Around 8,000 Barbados dollars (4,000 US dollars) more is spent in treating a non-survivor, compared to a survivor in our surgical ICU (Table II). Although decisions about the futility of care should never be taken considering exclusively the costs involved in treating the patient, the cost factor cannot be completely eliminated. We do not have an appropriate high dependency unit and/or a rehabilitation unit where chronically critically ill patients can be transferred for management involving lesser expenditure.

In summary, we have attempted to illustrate the problems of managing moribund patients in a surgical ICU of a developing country. Although we have ICU care facilities comparable to those in more developed countries, the ICU accommodates a limited number of patients. At a given time, when patients undergoing futile therapy occupy many of the beds, we are left with the conundrum of continuing the management for a prolonged period and with the cost involved in treating such patients borne by the government exchequer. In the future, we hope to obtain legislation, rectify the underlying problems and utilize the ethical committee to facilitate a smooth application of the concept of medical futility in our ICU.

\section{References}

1 Joralemon D. Reading futility: reflections on a bioethical concept. Camb Q Healthc Ethics 2002; 11 :

127-33.

2 Hariharan S, Moseley HSL, Kumar AY. Outcome evaluation in a surgical intensive care unit in Barbados. Anaesthesia 2002; 57: 434-41. 
3 Rubenfeld GD, Curtis JR, End-of-Life Care in the ICU Working Group. End-of-life care in the intensive care unit: a research agenda. Crit Care Med 2001; 29: 2001-6.

4 Nierman DM. A structure of care for the chronically critically ill. Crit Care Clin 2002; 18: 477-91.

5 Medical futility in end-of-life care. Report of the Council on Ethical and Judicial affairs. JAMA 1999; 281: 937-41.

6 Halevy A, Brody BA. A multi-institution collaborative policy on medical futility. JAMA 1996; 267: 571-4.

7 Asch $D A$. The role of critical care nurses in euthanasia and assisted suicide. N Engl J Med 1996; 334: 1374-9.

8 The SUPPORT Principal Investigators. A controlled trial to improve care for seriously ill hospitalized patients. The study to understand prognoses and preferences for outcomes and risks of treatments (SUPPORT). JAMA 1995; 274: 1591-8.

9 Curtis JR, Park DR, Krone MR, Pearlman RA. Use of the medical futility rationale in do-not-attempt-resuscitation orders. JAMA 1995; 273: 124-8.

10 Faber-Langendoen $K$. The clinical management of dying patients receiving mechanical ventilation. A survey of physician practice. Chest 1994; 106: 880-8.

11 Pochard F, Azoulay E, Chevret S, et al. French intensivists do not apply American recommendations regarding decisions to forgo life-sustaining therapy. Crit Care Med 2001; 29: 1887-92.

12 ten Have HAMJ, Welie JVM. Euthanasia in the Netherlands. Crit Care Clin 1996; 12: 97-108.

13 Diem SJ, Lantos JD, Tulsky JA. Cardiopulmonary resuscitation on television. Miracles and misinformation. N Engl J Med 1996; 334: 1578-82.

$14 \operatorname{Brody} H$. Bringing clarity to the futility debate: don't use the wrong cases. Camb Q Healthe Ethics 1998; 7: 269-73.

15 Murphy DJ, Burrows D, Santilli S, et al. The influence of the probability of survival on patients' preferences regarding cardiopulmonary resuscitation. N Engl J Med 1994; 330: 545-9.

16 Crausman RS, Armstrong JD II. Ethically based medical decision making in the intensive care unit. Residency teaching strategies. Crit Care Clin 1996; 12: 71-84.

17 Wagner JT, Higdon TL. Spiritual issues and bioethics in the intensive care unit. The role of the chaplain. Crit Care Clin 1996; 12: 15-27.

18 Youngner SJ. Medical futility. Crit Care Clin 1996; 12: 165-78. 